\title{
LOS TRATADOS MULTIPOLARES. UNA NUEVA GENERACIÓN DE TRATADOS INTERNACIONALES
}

\author{
Víctor Manuel RoJAS AMANDI*
}

RESUMEN: En el moderno derecho internacional público de cooperación ha nacido un nuevo tipo de tratados internacionales que se caracteriza por regular materias que se relacionan directamente con las necesidades de bienestar de los particulares. Dichos tratados, a los que Albert Bleckmann denomina como tratados multipolares, se caracterizan por fundamentar relaciones jurídicas múltiples, en donde todos los Estados parte tienen el mismo interés jurídico de que todos los demás signatarios cumplan con sus obligaciones contractuales. Un análisis de los elementos más importantes de dichos tratados es lo que se propone el autor en el presente artículo.

ABSTRACT: In the modern International Law of Cooperation a new form if international agreement has emerged characterized by regulating issues directly related to the wellbeing of individuals. These agreements, to which the German Albert Bleckmann calls multipolar treaties, are characterized by founding multiple legal relations in which the States Parties have the same legal interest as the rest of the Parties that fulfill their contractual duties. The author of this article makes an analysis of the most important elements of this treaty.

RÉSUMÉ: Dans le moderne droit international de la coopération, une nouvelle forme de traité international a surgi en relation directe avec les besoins de bien-être des civils. La caractéristique de ceux traités, dénommés traités multipolaires par l'allemand Albert Bleckmann, c'est de fonder des relations multiples où tous les Etats membres ont le même intérêt que les autres signataires d'accomplir leurs obligations contractuelles. L'auteur de cet article fait une analyse des éléments les plus importants de ceux traités.

* Doctor en derecho por la Universidad de Heidelberg en Alemania y profesor de tiempo completo de la Universidad Iberoamericana. 
SUMARIO: I. Introducción. II. El derecho internacional de cooperación. III. El derecho internacional de cooperación y los tratados internacionales. IV. Los tratados multipolares. V. Conclusiones.

\section{INTRODUCCIÓN}

Muchas fueron las transformaciones que sufrió el derecho internacional público durante el siglo XX. Dentro de las más importantes se encuentra el nacimiento de un derecho internacional público de cooperación, el que se caracteriza por la instrumentalización del trabajo conjunto de los Estados en tareas que tradicionalmente no se habían considerado como materia de las relaciones internacionales. Dentro de éstas se encuentran: la protección de los derechos humanos y del medio ambiente; las condiciones de trabajo de los trabajadores; la lucha contra la corrupción; las relaciones privadas transfronterizas, etcétera. La realización de los objetivos del derecho internacional público de cooperación tiene un efecto más que en los intereses soberanos de los mismos, en la calidad de vida de sus ciudadanos. El ser humano, junto a los intereses soberanos de los Estados, se ha vuelto así un objetivo de primordial importancia para el derecho internacional público.

La cooperación interestatal le ha dado un impulso de gran envergadura al desarrollo de las organizaciones internacionales; ha flexibilizado el concepto de capacidad jurídica internacional, permitiendo que personas privadas puedan apelar a instancias de solución de diferencias internacionales y ha hecho necesaria la participación de la sociedad civil en las labores de supervisión del cumplimiento de las obligaciones internacionales por parte de los Estados. Pero sobre todo, la cooperación internacional ha dado lugar a una nueva generación de tratados internacionales, a los que el profesor de la Universidad Münster en Alemania, Albert Bleckmann ${ }^{1}$ ha denominado "tratados multipolares" — multipolare Vert-

1 Albert Bleckmann es uno de los autores de derecho internacional público, de derecho europeo y de derecho público más importantes en Alemania. Bleckmann estudió derecho en Alemania y en Francia. Obtuvo también los grados de doctor en derecho en ambos países. La habilitación para optar por la cátedra en derecho la obtuvo en la Universidad de Heidelberg. A partir de 1976 se desempeñó como profesor en la Facultad de Derecho de la Universidad de Münster de donde fue emeritado en 1998. Además de ser un autor de múltiples libros de texto y artículos en derecho internacional público, derecho público, derecho europeo y derecho comparado, el profesor 
äge- - Los tratados multipolares se diferencian de los tradicionales tratados bipolares, tanto por las materias que regulan y que se relacionan directamente con las necesidades de bienestar de los ciudadanos, como por el hecho de que sus disposiciones fundamentan relaciones jurídicas múltiples, en donde todos los Estados parte tienen el mismo interés jurídico de que todos los otros cumplan sus obligaciones contractuales. Además, muchos tratados multipolares desarrollan ordenaciones jurídicas que regulan relaciones entre sujetos privados y que deben ser aplicadas de manera directa por las autoridades nacionales judiciales o administrativas. Esto significa que la autoridad que concluye el tratado sustituye a los legisladores nacionales y que el cumplimiento de las obligaciones internacionales se lleva a cabo en el ámbito interno de los Estados.

En el presente artículo nos proponemos exponer la teoría de los tratados multipolares de Bleckmann ${ }^{2}$ siguiendo muy de cerca sus ideas fundamentales y procurando complementarlas con múltiples ejemplos. En el capítulo II se expondrán las características del derecho internacional público de cooperación. El capítulo III analizará los efectos que ha tenido el derecho internacional público de cooperación sobre el derecho de los tratados internacionales. Los tratados multipolares serán objeto del capítulo IV. Después de analizar su concepto, se estudiará la estructura de las relaciones jurídicas que caracteriza a este tipo de tratados internacionales. El cumplimiento de las obligaciones de los tratados multipolares constituye la parte central del capítulo IV e incluye el análisis del cumplimiento entre los Estados parte y de los instrumentos preventivos de cumplimiento. Finalmente, se expondrán a manera de conclusión los resultados más importantes del análisis.

\section{EL DERECHO INTERNACIONAL DE COOPERACIÓN}

La teoría de los tratados multipolares se ubica dentro del moderno derecho internacional público de cooperación. Éste se desarrolló durante

Bleckmann ha fungido en diversas ocasiones como abogado del gobierno de la República Federal de Alemania ante el Tribunal de Justicia de las Comunidades Europeas con sede en Luxemburgo.

2 La teoría de los tratados multipolares de Bleckmann se ha expuesto básicamente en Bleckmann, Albert, "Zur wandlung der Strukturen des Völkerrechtsverträge - Theorie des multipolaren Vertrages_", Archiv des Völkerrechts, vol. 34, 1996, pp. 218-236. También en id., Allgemeine Staats und Völkerrechtslehre, Köln, Carl Heymanns Verlag, 1995, pp. 696-781, se encuentran importantes contribuciones a la teoría de los tratados multipolares. 
el siglo XX al lado del tradicional derecho internacional público de coexistencia, el que se organizó con base en el concepto de soberanía exterior de los Estados y cuyo objeto fundamental fue la preservación de la seguridad y orden público internacional. Las limitaciones de libertad de actuación de los Estados y sus derechos de defensa frente a otros Estados, para mantener la integridad de su territorio, de sus ciudadanos y de su organización, son derivaciones del derecho internacional público de coexistencia. De ahí su denominación. ${ }^{3}$

El derecho internacional público ha venido evolucionando de un derecho de mera coexistencia a un derecho de cooperación. El derecho internacional clásico era un derecho de mera coexistencia que, por una parte, se limitaba a establecer las fronteras de los ámbitos temporal, material, espacial y personal de los diversos sectores de la soberanía. Por la otra, regulaba las relaciones de los Estados entre sí y determinaba ciertos estándares para el trato recíproco de los órganos de los Estados y de los ciudadanos, tanto en la guerra como en la paz.

Junto al derecho internacional de coexistencia, que aún actualmente conserva gran importancia, se ha venido desarrollando un derecho de cooperación que ha sido inspirado por la Carta de las Naciones Unidas y por la correspondiente de su predecesora, la Liga de las Naciones, y que encuentra en la emisión de la Declaración de los Principios de Derecho Internacional relativo a las Relaciones Pacíficas y Cooperación entre los Estados $^{4}$ de 24 de octubre de 1970 uno de sus desarrollos más importantes al promover la cooperación y el trabajo común. Este derecho de cooperación se caracteriza por prescribir obligaciones para llevar a cabo actividades interestatales de muy diverso tipo, en donde la participación de las organizaciones internacionales adquiere gran importancia. De esta forma, en tanto que el derecho internacional público de coexistencia prescribe básicamente obligaciones de no hacer, el derecho internacional público de cooperación prescribe fundamentalmente obligaciones de hacer. $^{5}$

3 Krüger, Helmut, "Souveranität und Staatengemeinschaft", Berichte Deutsche Gesellschaft für Völkerrecht, t. 1, 1957, pp. 1 y ss.; Friedmann, John, The changing structure of International Law, Oxford, Oxford University Press, 1964.

4 Resolución 2625 (XXV), UN Doc. A/L. 600.

5 Véase, al respecto, Verdross y Simma, Universeles Völkerrecht, Berlín, Duncker \& Humblot, 1984, pp. 41 y 264. 
El derecho internacional público de cooperación es resultado del crecimiento de una intensificación sin precedente de las relaciones internacionales entre los Estados. Ésta se produce cuando ellos perdieron la capacidad de satisfacer por sí mismos los intereses de bienestar de sus ciudadanos. Una de las materias donde la cooperación se ha hecho tan imprescindible, como casi en ningún otro caso, es el de la protección del medio ambiente. Esto debido a que los problemas medioambientales se encuentran asociados con intereses económicos — ventajas competitivas que surgen debido a diferencias en los estándares de protección ambiental-y sociales — protección de empleos frente a los objetivos medioambientales_- Esta interrelación entre los problemas ambientales y los económicos y sociales trasciende las fronteras estatales y se relaciona con la producción de alimentos y con el crecimiento de la población en los países en vías de desarrollo. ${ }^{6}$

Las transformaciones que dieron lugar al cambio de la estructura del derecho internacional público tradicional, llevaron a una reconceptualización del principio de soberanía ${ }^{7}$ para reconocer que ésta no era un fin en sí mismo, sino un medio para satisfacer los intereses de bienestar de los pueblos. ${ }^{8}$ Cuando los intereses de bienestar de los ciudadanos de los diferentes Estados se homologaron, lo que fue posible con la internacionalización de los derechos humanos ${ }^{9}$ y de la consecuente solidaridad entre los pueblos, también se identificaron los intereses de los Estados. Fue así como han surgido intereses generales de la comunidad internacional y nuevas tareas para el Estado que sólo en la vía de la cooperación internacional se pueden satisfacer. De esta forma, es como las tradicionales materias del derecho internacional público de guerra, extranjería, relaciones diplomáticas y consulares, etcétera, se han expandido significativamente al ámbito de los derechos humanos, a las relaciones económicas y comerciales internacionales, a las relaciones sociales, a la ayuda al desarrollo y a la protección de la naturaleza del medio ambiente y del patrimonio cul-

6 Kilian, Michael, Umweltschutz durch internationale Organisationen. Die Antwort des Völkerrechts auf die Kriese der Umwelt, Berlín, Duncker \& Humblot, 1987, p. 25.

7 Bleckmann, Albert, "Das Souveranitätsprinzip im Völkerrecht", Archiv des Völkerrechts, vol. 23,1985 , pp. 450 y ss.

8 Bleckmann, Albert, op. cit., nota 2, p. 219.

9 Häberle y Martens, "Grundrechte im Leitungsstaat", Veröffentlichungen der Vereinigung der Deutschen Staatsrechtslehrer, t. 30, 1972, p. 7. 
tural, etcétera. ${ }^{10}$ Esta nueva etapa se caracteriza por una multitud de tratados internacionales que se han preparado en conferencias con ayuda de organizaciones internacionales de alcance universal o regional, y que tienden a establecer regulaciones de cierto detalle cuyos destinatarios, más que ser órganos estatales, son sujetos privados. Asimismo, en la etapa del derecho internacional público de cooperación ha nacido un derecho internacional público obligatorio - ius cogens - y el surgimiento de obligaciones internacionales que no sólo valen frente a otros Estados, sino también frente a la comunidad internacional. Esto debido a que los Estados no pueden satisfacer por su propia cuenta y con vista a sus intereses particulares dichos intereses generales.

Para ejemplificar con cierto detalle esta situación, podemos referirnos a las convenciones en materia de lucha en contra de la corrupción. Tradicionalmente se reconoció que el combate contra las prácticas corruptas quedaba reservado a las políticas públicas internas de los Estados. Sin embargo, durante los últimos veinte años la intensificación del comercio internacional dio lugar a una corrupción sin precedentes en el mundo, la que fue calificada como la "gran corrupción" y que en sectores tales como la venta de material militar; la transferencias de bienes de capital involucrados en grandes proyectos; las obras públicas de gran envergadura; la compra-venta de materias primas masivas; el pago a profesionistas por informes técnicos y las auditorías, llegaron a adquirir proporciones alarmantes. Esto se debió, entre otras cosas, a factores tales como al hecho de que las empresas transnacionales cuentan con un potencial económico mayor que muchos Estados; a que los negocios internacionales cada día crecen más; a que en los países en vías de desarrollo los salarios de la burocracia suelen ser muy bajos y las condiciones del trabajo no son buenas; a las asimetrías económicas, jurídicas, sociales, políticas que existen entre países altamente desarrollados y países en vías de desarrollo; a las transacciones de divisas a través de sistemas informáticos, etcétera. ${ }^{11}$

Por qué causa la "gran corrupción" se convirtió en un problema internacional, se mencionan varios fenómenos. En primer término, debido a que las prácticas corruptas funcionan de tal manera que falsean el siste-

10 Graf Vitzhum, Wolfgang, "Vorbemerkung”, Graf Vitzthum, Wolfgang (ed.), Völkerrecht, Berlín, Walter de Gruyter, 1997, p. 18.

11 Malem, Jorge, Globalización, comercio internacional y corrupción, Barcelona, Gedisa, pp. $39-43$. 
ma de competencia internacional al no permitir que los productos económicamente más viables sean los que prevalezcan en el mercado internacional, y de esta forma al asegurar el monopolio de productos y empresas poco competitivas. Asimismo, se mencionan como efectos de las prácticas corruptas su efecto sobre la toma de decisiones políticas; el aumento del costo de bienes y servicios; las crisis políticas a que pueden dar lugar; el hecho de que un acto de corrupción normalmente debe ir seguido de otros actos del mismo tipo, y que facilita la generación de actividades ilícitas, tales como el contrabando. ${ }^{12}$

Adicionalmente, las medidas estrictamente nacionales de lucha contra la corrupción, como la Foreign Corupt Practice Act de los Estados Unidos de 1977, mostraron su incapacidad para hacer frente a los desafíos que plantearon las especiales prácticas de corrupción que se relacionaron con las transacciones económicas internacionales. De esta forma, se hizo patente la necesidad de adoptar medidas multilaterales obligatorias que llevaran a una armonización de los derechos internos de la materia, a una mayor cooperación internacional, a la extensión del ámbito de aplicación espacial de los ilícitos sancionados por las normas nacionales también para actos cometidos fuera de los territorios de los Estados parte y al intento para ampliar la base jurídica para la extradición en caso de delitos relacionados con la corrupción. ${ }^{13}$ Fue así como, durante la última década del siglo XX, se negociaron bajo los auspicios de diferentes organizaciones internacionales varios instrumentos jurídicos que regulan el problema de la corrupción. En el ámbito universal destaca la Convención de las Naciones Unidas contra la Delincuencia Organizada Transnacional. ${ }^{14}$ En Europa se abrió a firma el 27 de enero de 1999 el Convenio de Derecho Penal sobre la Corrupción del Consejo de Europa y el 4 de noviembre de ese mismo año el Convenio de Derecho Civil sobre la Corrupción del Consejo de Europa. Asimismo, el Consejo de la Unión Europea había aprobado el 26 de julio de 1995 el Convenio establecido sobre la base del artículo k.3 del Tratado de la Unión Europea, relativo a la protección de los intereses financieros de las Comunidades Europeas. En el Continente Americano existe la Convención Interamericana contra

12 Ibidem, pp. 44-69.

13 Cabe destacar que la ONU desde 1975 -Resolución 3514 de 15 de diciembre- mostró su preocupación por ciertas prácticas corruptas llevadas a cabo por empresas transnacionales.

14 Aprobada por la Asamblea General en su resolución de 55/25, de 15 de noviembre de 2000, y abierta a firma del 12 al 15 de diciembre de 2000, en Palermo, Italia. 
la Corrupción misma que fue aprobada en una Conferencia Interamericana Extraordinaria y abierta a la firma en Caracas el 29 de marzo de 1996 y en vigor el 6 de marzo de 1997. Finalmente, en el marco de la Organización de Cooperación y Desarrollo Económicos se firmó el 17 de diciembre de 1997 la Convención para Combatir el Cohecho de Funcionarios Públicos Extranjeros en Transacciones Comerciales Internacionales.

\section{EL DERECHO INTERNACIONAL DE COOPERACIÓN Y LOS TRATADOS INTERNACIONALES}

En el derecho de los tratados internacionales, el derecho internacional público de cooperación ha presentado cuatro características fundamentales. En primer lugar, los tratados internacionales tienden a sustituir mediante la codificación al derecho de costumbre internacional, el que se ha caracterizado por la poca precisión de sus normas y por obligaciones de omisión. La labor de la Comisión de Derecho Internacional de Naciones Unidas tiene por objeto precisar mediante su codificación, las normas de costumbre internacional, ante los desafíos que plantea la intensificación de las relaciones internacionales.

Asimismo, se advierte un desarrollo y crecimiento de resoluciones de organizaciones internacionales y, sobre todo, de los instrumentos de soft law, esto es de normas jurídicas no obligatorias que se negocian entre Estados. ${ }^{15}$ Éstas contribuyen a flexibilizar el orden jurídico internacional, a influir sobre las políticas públicas nacionales mediante formas persuasivas — prevención en lugar de represión, cooperación en lugar de egoísmo, etcétera - y a servir como una etapa previa - función de pré-droit - a las negociaciones de obligaciones internacionales —en caso de tratados internacionales-, o de preparación de una opinio iuris - en caso de obligaciones de costumbre-, mediante la sensibilización de la opinión pública internacional. ${ }^{16}$ El soft law ha llegado a ser así, gracias a su prestigio, el "caballo de Troya" que cruza los muros del tradicional derecho internacional público para contribuir a su desarrollo, sin

15 Sobre el fenómeno del soft law, véase Shelton, Dinah, Law, Non-Law and the Problem for Soft Law, disponible en: http://www.asil.org/shelton.pdf.

16 Véase, al respecto, Dupuy, René, "Declaratory Law and Programmatory Law: From revolutionary custom to soft law", en Ackermann, Robert et al. (eds.), Declarations on Principles, Leyden, 1977, pp. 252 y ss.; y Thürer, Daniel, "Soft law eine neue Form von Völkerrecht?", Zeitschrift für schweizerisches Recht, t. 104 , 1985, pp. 429 y ss. 
la necesidad de obligar a nadie. Los instrumentos de soft law también resultan muy útiles en las negociaciones de normas concretas en tratados internacionales. Esto debido a que, cuando las obligaciones concretas a negociar pueden resultar onerosas para los Estados, se estila una negociación diferida en varias etapas. De esta forma, se comienza negociando un acuerdo marco que deja suficiente margen para una definición lo más ventajosa posible de las obligaciones concretas que habrán de contraerse por los diferentes Estados parte, lo que puede hacerse en simples declaraciones no vinculantes — esto es, en normas de soft law-, en protocolos, o en combinaciones entre declaraciones y protocolos.

En tercer término, destaca la sustitución de tratados bilaterales por tratados multilaterales. Esto se debe, en principio, a que existe un interés general de todos los Estados de la comunidad internacional en una regulación común y uniforme de determinados sectores. Este interés general resulta por demás evidente en aquellos casos en que, para alcanzar sus fines, el orden jurídico internacional debe prescribir para todos los Estados del mundo o, para un grupo de ellos, una regulación uniforme. Así, por ejemplo, debido a que como lo establece el Preámbulo de la Convención sobre Diversidad Biológica, la conservación de la diversidad biológica representa un interés común de la humanidad, se prescribe en el artículo 8 de la misma que, los Estados parte deben proteger a las plantas y animales en su ambiente natural, entre otras cosas, mediante establecimiento de zonas de protección como parques nacionales, lo que implica cierta armonización en las regulaciones nacionales de la materia y un trabajo de asistencia y cooperación entre los Estados parte. De igual forma, como lo demuestran las negociaciones de los acuerdos paralelos del Acuerdo de Libre Comercio de América del Norte, la armonización y aseguramiento del cumplimiento de las regulaciones nacionales en materia del trabajo y del medio ambiente, se ha visto motivada por la necesidad de evitar falseamientos al sistema de competencia que se pudieren originar debido a que las regulaciones nacionales establecen diferentes estándares de protección. ${ }^{17}$

17 En el marco de los tratados firmados para la creación de un Área de Libre Comercio en América del Norte, la armonización de los principios e instrumentos de aplicación del derecho interno del medio ambiente de los países signatarios, tiene por objeto evitar que existan diferencias en la intensidad de aplicación de las normas medioambientales en los tres países, que pudieran conducir a falseamientos en el sistema internacional de competencia dentro de la zona de libre comercio. De esta forma, dichas obligaciones son medios para la realización del objetivo del 
Asimismo, los tratados multilaterales le ofrecen a los países en vías de desarrollo la oportunidad de hacer valer el principio de mayoría frente al mayor poder económico de los países altamente industrializados. De esta forma, no son pocos los tratados multilaterales que superando el principio de reciprocidad en las contraprestaciones, establecen criterios que consideran de manera especial la situación de los países en vías de desarrollo. Así, según lo dispuesto por los artículos 3 y 4 de la Convención de Cambio Climático, ${ }^{18}$ la responsabilidad de los Estados parte para combatir el cambio climático se basa en el principio de responsabilidad común pero diferenciada —common but differentiated responsabilities - . Para efectos prácticos, esto significa que corresponde a los Estados industrializados cumplir obligaciones más estrictas. Lo mismo sucede con la regulación especial y más ventajosa que establece el artículo 5 del Protocolo de Montreal sobre Sustancias que Dañan la Capa de Ozono ${ }^{19}$ por cuanto hace al uso anual de las sustancias reguladas. También, en 1964 después de un movimiento encabezado por los países menos industrializados al que se denominó Anti-GATT se logró la inclusión de la Parte IV del Acuerdo General sobre Aranceles y Comercio que establece un sistema generalizado de preferencias en favor de los países en vías de desarrollo.

Finalmente, los tratados multilaterales prevén relaciones jurídicas multipolares que no sólo pretenden garantizar la protección de los derechos subjetivos de los Estados parte, sino también la defensa de los intereses generales de la comunidad internacional. En este caso se hace patente la consideración de los intereses generales en los tratados internacionales

ACAAN de evitar que se creen distorsiones o nuevas barreras en el comercio internacional. Por su parte, en el capítulo XI del Tratado de Libre Comercio de América del Norte también se prevén dos obligaciones que tienen por objeto evitar que se creen distorsiones al sistema internacional de competencia económica. Por una parte, por la fracción 2 del artículo 1114 del acuerdo comercial se encuentra prohibido que los Estados signatarios conserven su capacidad de competencia en el mercado regional, mediante la renuncia o la oferta de renuncia a aplicar la legislación medioambiental o mediante la derogación u oferta de derogación de las medidas medioambientales. Asimismo, se encuentra prohibido utilizar como medio para disminuir los costos de producción, la derogación u oferta de derogación de las medidas medioambientales, o la renuncia o la oferta de renuncia a aplicar la legislación medioambiental. Véase, al respecto, Rojas Amandi, Víctor, La protección del medio ambiente en el TLCAN y la OMC, México, Oxford University Press, 2000, pp. 261 y ss.

18 El texto se encuentra disponible en International Legal Materials 92, p. 849.

19 Se puede encontrar el texto en International Legal Materials 26, p. 1541. 
comerciales y sobre derechos humanos, en los acuerdos de armonización jurídica y de no proliferación de armas nucleares.

Debido a que los tratados multipolares no establecen más vínculos para relaciones bilaterales, sino que de diferente manera unen a todos los Estados parte entre sí, se tienden a confundir los estatus de acreedores y deudores. Con esto, el concepto de reciprocidad se elimina. Este sería el caso de los daños que se ocasionan a la capa de ozono por el consumo de ciertas sustancias químicas, toda vez que no se podría determinar con claridad qué Estado sería responsable de qué daño a la misma y cuál o cuáles pudieran emprender acciones por los daños que el adelgazamiento de dicha capa pudiera ocasionar. ${ }^{20}$

Como bien lo demuestran los tratados en materia de derechos humanos, en los tratados multilaterales se debe renunciar al recurso de la reciprocidad, debido a que los individuos son incapaces de hacer frente por su cuenta a las conductas de órganos estatales que violentan sus derechos fundamentales y debido a que, el respeto a los derechos humanos no puede quedar sujeto a la condición de que otros Estados también respeten los correlativos de sus ciudadanos.

\section{LOS TRATADOS MULTIPOLARES}

\section{Concepto}

Los tratados multipolares establecen obligaciones en cuyo cumplimiento se encuentra interesada la generalidad de todos los Estados parte. En este tipo de tratados el cumplimiento de las obligaciones se puede exigir por la totalidad de los Estados o, por un solo Estado a todos los demás. A diferencia de éstos, los tratados bipolares, los que no obstante que puede ser multilaterales, establecen relaciones jurídicas bilaterales de intercambio mutuo. ${ }^{21}$

Los tratados multipolares suelen buscar tres objetivos fundamentales: a) La coordinación y armonización del derecho interno de los Estados parte; b) Establecer el principio de responsabilidad compartida reforzado con medidas de tipo preventivas — como la presentación de infor-

20 Faries, Timothy, "Clearing the air: an examination of International Law on the Protection of the ozone layer", Alberta Law Review, núm. 28, 1990, p. 827.

21 Bleckmann, Albert, op. cit., nota 2, p. 225. 
mes y la práctica de inspecciones - para hacer frente a un problema común - por ejemplo para la defensa de un "patrimonio común de la humanidad"- $\mathrm{y}$; c) Establecer estructuras de cooperación mediante la creación de instancias intergubernamentales.

Por cuanto a su contenido, los tratados multipolares cuentan con cuatro características fundamentales: a) Fundan un verdadero orden jurídico objetivo, por lo que en ocasiones se les suele denominar "tratados ley"; b) Sus objetivos son la satisfacción de los intereses comunes de todos los Estados parte; c) Su diseño normalmente es abierto facilitando la adhesión de nuevos Estados parte, pues existe interés general de que cada vez sean más Estados los que formen parte del acuerdo; ${ }^{22}$ y d) La estructura de las obligaciones y sanciones refleja el interés que tienen todos los Estados parte para que las disposiciones del acuerdo se cumpla de igual manera en todos los Estados miembro.

\section{Estructura de las relaciones jurídicas en los tratados multipolares}

En la nueva era del derecho internacional público, los derechos subjetivos de los Estados no han desaparecido, sin embargo, el desarrollo de los intereses generales de la comunidad internacional trae como consecuencia que la libertad de actuación de los Estados y sus derechos de defensa se hayan complementado con todos los intereses modernos de bienestar.

Los tratados multipolares tienen como objeto la satisfacción de los intereses generales públicos de todos los Estados miembro. Por lo mismo, este tipo de tratados establecen obligaciones erga omnes y en consecuencia hace nacer derechos subjetivos a favor de todos los Estados parte. Con esto surgen relaciones jurídicas no entre Estados, sino entre cada Estado parte con todos los otros Estados parte. Esto significa que, ante una violación, el tratado se puede suspender o renunciar no en las relaciones bilaterales entre dos Estados parte, sino en relación a todos los Esta-

22 Esto, no obstante de que se trate de acuerdos regionales preparados por organismos también regionales. De esta forma, las convenciones emanadas de la Comisión Interamericana de Derecho Internacional Privado (CIDIP) tienen como rasgo común el que a ellas pueda adherirse cualquier Estado, sin importar si pertenece o no a la Organización de Estados Americanos o al continente americano. Véase, al respecto, Contreras Vaca, Francisco José, Derecho internacional privado. Parte especial, Oxford University Press, 1998, p. 74. 
dos parte. Sin embargo, debido a que el interés general de todos los Estados es el cumplimiento de las obligaciones contractuales, la suspensión y la renuncia pierden su atractividad como sanciones y dejan su lugar a sanciones que sirvan para conminar a las partes al cumplimiento del tratado, tales como represalias o al derecho de reparación del daño. Así, por ejemplo, las contribuciones monetarias que se pueden imponer como sanción a los Estados parte que violen sus obligaciones establecidas en el Acuerdo de Cooperación Ambiental de América del Norte (ACAAN), según lo dispuesto en el numeral 3 del anexo 34 del acuerdo, se destinan al financiamiento de las actividades directamente relacionadas con la protección del medio ambiente o para costear las medidas que se tomen con el fin de aplicar las disposiciones de la legislación ambiental de la parte demandada. En este sentido, dicha sanción tiene una función reparadora más que de control coercitivo. ${ }^{23}$

Debido a que, mediante la armonización de las normas entre naciones, en materia social y ambiental, se pretenden evitar un falseamiento de la competencia en una zona de integración económica, o mediante la unificación del derecho internacional privado, se busca la seguridad jurídica mediante una regulación estándar complementada por la aplicación de las normas internacionales por los jueces nacionales, entre los Estados parte de los acuerdos multipolares existe un fuerte interés de que las normas del mismo se cumplan de igual forma por todos los Estados parte. Las convenciones internacionales en materia de arbitraje son un digno ejemplo de este fenómeno. En efecto, quizá como en otras pocas materias, el de la regulación del arbitraje comercial ha sido objeto de armonización vía diversas convenciones internacionales, entre las que se encuentran: la Convención sobre el Reconocimiento y la Ejecución de Sentencias Arbitrales Extranjeras; el Convenio Europeo sobre Arbitraje Comercial Internacional; la Convención Interamericana sobre Arbitraje Comercial Internacional y el Tratado para la Armonización del Derecho de Negocios Africano, sin olvidar la Ley Modelo de la CNUDMI sobre Arbitraje Comercial Internacional que sin ser propiamente una convención sino un simple instrumento de soft law, constituye la base jurídica de aproximadamente cuarenta jurisdicciones locales. Este creci-

23 Véase Abbot, Frederick, "The NAFTA Environmental Dispute Settlement System as Prototype for Regional Integration Arrangements", Yearbook of International Environmental Law, núm. 4, 1994, p. 5. 
miento de las convenciones en materia de arbitraje fue la respuesta a la necesidad de proteger de manera más efectiva a la inversión extranjera en un época en que la misma se incrementó de manera significativa y ante la incapacidad de los tribunales nacionales para ocuparse de conflictos para los que las legislaciones internas ofrecen una regulación por demás limitada. Pues bien, debido a que el éxito del arbitraje comercial internacional radica en el reconocimiento y ejecución de laudos, mismo que se lleva a cabo por tribunales nacionales, los que pueden desestimar la solicitud de ejecución por motivos de orden público, en el último tiempo se han venido definiendo ciertos criterios mínimos como parte de dicho concepto y se han tratado de establecer con base en los contenidos de los clásicos derechos humanos que hoy día han alcanzado un reconocimiento universal. ${ }^{24}$ Con esto, se hace patente el interés de todos los Estados parte de las correspondientes convenciones para que todos ellos apliquen sus normas de la mejor manera sin abandonar la efectividad de las mismas a interpretaciones caprichosas de la excepción de orden público.

En los tratados bipolares se pueden distinguir dos casos con relación a la cuestión relativa a determinar en favor de quién crea derechos subjetivos un tratado. Por regla, en los términos de lo expresamente previsto en el acuerdo internacional de voluntades, se puede establecer claramente entre qué partes existen relaciones jurídicas bilaterales. Los tratados internacionales en materia de suministro de materias primas o de energía son un claro ejemplo de este caso. Un tercer Estado no tiene en estos casos derecho alguno para exigir que el Estado obligado a suministrar energía cumpla con la obligación que aquél tiene frente al Estado acreedor. En otros casos, el tratado multilateral establece condiciones muy claras para saber en qué caso un Estado concreto le puede exigir a otro en especial una prestación concreta. Este es el caso de algunos tratados de derecho internacional privado. En estos casos el tratado establece que sólo resulta válida una obligación frente a otros Estados que también sean parte del mismo. De esta forma, las relaciones jurídicas se establecen entre Estados parte y no existe causa para que un Estado que no sea parte pueda exigir el cumplimiento de obligaciones prevista en el tratado exclusi-

24 Véase Cremades, Bernardo y Cirns, David, "El arbitraje en la encrucijada entre la globalización y sus detractores", Revista Mexicana de Derecho Internacional Privado, vol. 11, 2002, pp. 89-95. 
vamente para Estados parte. Así, en los tratados bipolares se protegen los intereses particulares de los Estados parte contra conductas de otros Estados parte que violan las normas contractuales.

Por su parte, los tratados multipolares protegen los intereses generales de la comunidad internacional. Estos intereses generales se diferencian de los intereses soberanos de los Estados. Se trata de intereses de bienestar de los pueblos que se encuentran garantizados por los pactos de derechos humanos tanto universales como regionales. Debido a que en el derecho internacional público no existen instancias centrales de control del cumplimiento de las normas internacionales, los intereses generales deben ser hechos cumplir por los Estados mismos. Esto significa que los tratados multipolares fundamentan derechos subjetivos para todos los Estados parte. De aquí nace la necesidad de prever en varios de estos acuerdos el sometimiento obligatorio a un sistema de solución de diferencias.

\section{Cumplimiento de las obligaciones internacionales en los tratados multipolares}

\section{A. Entre Estados}

En los tratados bipolares resulta necesario que quien reclame el cumplimiento del mismo sea el Estado, para el cual el acuerdo internacional establece derechos subjetivos. Aquellos Estados que en consideración del caso concreto cuentan con un derecho subjetivo se establecen en los tratados bipolares, en la mayoría de las veces, de manera expresa. Cuando este no es el caso, se está a la regla según la cual, el Estado que tiene derechos subjetivos es aquél cuyos intereses se ven satisfechos con el cumplimiento del acuerdo.

En el caso de los tratados multipolares se protege el interés general de los Estados parte. Los tratados multipolares dan lugar al nacimiento de un sistema objetivo en el que todas las partes tienen los mismos intereses de que todos y cada uno de ellos cumplan las obligaciones objetivamente establecidas. Para este tipo de tratados las reservas adquieren una significación especial. Tampoco la renuncia al tratado puede resultar una sanción efectiva ante la violación de una obligación contractual.

En cuanto a las violaciones de las obligaciones contractuales a tratados multipolares, se dificulta aplicar la sanción que establece el artículo 
60 de la Convención de Viena sobre Derecho de los Tratados. Esto debido a que la suspensión o renuncia del tratado no representa una sanción efectiva, pues todos los demás Estados parte se encuentran interesados en que todos y cada uno de ellos cumpla con sus obligaciones internacionales. En consecuencia, hacer renunciar del tratado a un Estado que lo viola, atenta contra los objetivos del mismo, e incluso, puede beneficiar al Estado violador. Por otra parte, la exclusión de los Estados parte que violen el tratado imposibilita la satisfacción del interés general de la comunidad internacional.

Por otra parte, debido a que las normas de solución de concurrencias normativas de los tratados previstas en el artículo 36 de la Convención de Viena sobre Derecho de los Tratados se basan en la regla: "ley posterior deroga ley anterior", la misma resulta poco apta para aplicarse a obligaciones que se cumplen en muchos casos mediante el sistema jurídico interno de los Estados parte. De esta forma, si un juez nacional debe aplicar dos normas contractuales que se contradicen entre sí, necesariamente violará la norma de uno de los tratados para cumplir la del otro. Para este caso, el juez más bien debería, en vía de una interpretación teleológica, investigar cuál es la norma de conflicto que mejor puede dejar satisfechos los intereses de la voluntad de las partes. Debido a que dichos tratados deben satisfacer el interés general de la comunidad internacional, los derechos subjetivos de los Estados parte del primer tratado no se deben violar por las obligaciones del segundo, si ambos tratados buscan la satisfacción de los intereses generales. Cuando concuerden las normas de dos acuerdos multipolares, mediante la interpretación teleológica se debe conceder primacía a las obligaciones contractuales de aquél tratado multipolar que permita de mejor forma la satisfacción de los intereses de la comunidad internacional.

\section{B. Instrumentos preventivos de cumplimiento}

Este tipo de tratados desarrollan nuevos instrumentos de cumplimiento de las obligaciones. Instrumentos de prevención, de control, monitoreo, planificación, administración internacional — cooperación científica, organización de comisiones internacionales, establecimiento de estándares, coordinación de redes para intercambio de información-, etcétera. 
De esta forma, de la praxis de la Organización Internacional del Trabajo y de las diversas organizaciones internacionales que se ocupan con los derechos humanos se han desarrollado los sistemas de información - reporting - como instrumentos que contribuyen al cumplimiento de las obligaciones. También en las convenciones de protección al medio ambiente se encuentra previsto este instrumento, estableciendo la obligación de los Estados parte de presentar informes sobre las medidas que se estén tomando para implementar las disposiciones de los acuerdos en el ámbito interno. ${ }^{25}$ Con este tipo de medidas se logra ejercer presión sobre los Estados al hacerles notar la forma en que se encuentran cumpliendo sus obligaciones y exhibir ante sus contrapartes las insuficiencias que estén mostrando en el cumplimiento de sus obligaciones internacionales.

Otro instrumento complementario es la inspección — supervisiónla que en la mayor parte de las ocasiones se encuentra a cargo de una instancia que crea el acuerdo. ${ }^{26}$ En este caso se trata de que una instancia internacional más bien de carácter técnico que revise de qué manera los Estados parte están cumpliendo con sus obligaciones. Así, por ejemplo, para la vigilancia en la aplicación de las disposiciones de la Convención Interamericana contra la Corrupción, se acordó en la Asamblea General de la Organización de Estados Americanos que tuvo lugar en Costa Rica del 3 al 5 de junio de 2001, poner en marcha los compromisos de Québec de abril del mismo año, consistentes en la creación de un mecanismo de seguimiento para la Convención. De esta forma, se previó la creación de un Comité de Expertos. Instalado el comité, emitió su Reglamento y Normas de Procedimiento en su primera reunión en la sede de la Organización en Washington, lo que sucedió entre los días 14 y 18 de enero de 2002. Además de las normas de organización y toma de decisiones, el reglamento prevé un procedimiento de análisis que consiste en la elaboración de un cuestionario especial que se remite al Estado parte correspon-

25 Artículo VII de la Convención para Regular el Comercio Internacional de las Especies de Flora y Fauna en Peligro de Extinción; artículos 11 y 17 de la Convention for the Prevention of Marine Pollution from Land-Based Sources; artículo 13 de la Convención de Basilea sobre Transporte de Desechos Peligrosos; artículo 12 de la Convención sobre Cambio Climático; capítulo 39.7 de la Agenda 21.

26 Algunos ejemplos son los artículos 10, 12 y 13 de la Convención de Cambio Climático; el artículo 23 de la Convention for the Protection of the Marine Environment of the North East Atlantic; artículo 10 de la Convention on Long Range Transboundary Air Pollution; artículo 7 del Treaty Concerning Co-operation in Matters of Water Economy in the Danube Basin; artículo 51 de la Convention on the Regulation of Antartic Mineral Resources Activities. 
diente al que se debe responder por éste en el plazo que el comité le fije (artículo 21). Habiendo recibido el cuestionario y analizada la información se prepara un informe preliminar (artículo 23) el que se discute y revisa con los expertos del Estado parte analizado (artículo 24) y en una reunión del Comité de Expertos se prepara un informe final por cada Estado, con las recomendaciones colectivas y acciones para reforzar la cooperación hemisférica, el cual, después de ser remitido a la Conferencia de los Estados parte, se hace público (artículo 26). Asimismo, se puede disponer la realización de visitas a los Estados parte para supervisar de qué forma se encuentran cumpliendo sus obligaciones contractuales (artículo 32).

Como bien se puede apreciar por los trabajos de la Organización Internacional de la Energía Atómica (IAEA), principalmente se trata de inspecciones de carácter preventivo y menos de inspecciones que tengan por objeto proponer soluciones a problemas ocasionados por el incumplimiento de obligaciones internacionales.

\section{CONCLUSIONES}

1. En el siglo XX ha surgido, al lado del tradicional derecho internacional público de coexistencia, el derecho internacional público de cooperación. Como parte de éste se han desarrollado un tipo especial de tratados internacionales que tienen por objeto primordial la satisfacción de las necesidades de bienestar de los seres humanos. Además, este tipo de tratados en muchas ocasiones se deben llevar a la práctica por los órganos de aplicación del derecho interno de los Estados parte.

2. El derecho internacional clásico ha sido un derecho de mera coexistencia que, por una parte, se limitaba a establecer las fronteras de los ámbitos temporal, material, espacial y personal de los diversos sectores de la soberanía. Por la otra, regulaba las relaciones de los Estados entre sí y determinaba ciertos estándares para el trato recíproco de los órganos de los Estados y de los ciudadanos, tanto en la guerra, como en la paz. Por su parte, el derecho internacional público de cooperación se caracteriza por prescribir obligaciones para llevar a cabo actividades interestatales de muy diverso tipo, en donde la participación de las organizaciones internacionales adquiere gran importancia. De esta forma, en tanto que el derecho internacional público de coexistencia, prescribe básica- 
mente obligaciones de no hacer, el derecho internacional público de cooperación prescribe fundamentalmente obligaciones de hacer.

3. En el derecho de los tratados internacionales, el derecho internacional público de cooperación ha presentado cuatro características fundamentales. En primer lugar, los tratados internacionales tienden a sustituir mediante la codificación al derecho de costumbre internacional, el que se ha caracterizado por la poca precisión de sus normas y por obligaciones de omisión. En segundo término, se advierte un desarrollo y crecimiento de resoluciones de organizaciones internacionales y, sobre todo, de los instrumentos de soft law, esto es de normas jurídicas no obligatorias que se negocian entre Estados. En tercer lugar destaca la sustitución de tratados bilaterales por tratados multilaterales. Finalmente, los tratados multilaterales prevén relaciones jurídicas multipolares que no sólo pretenden garantizar la protección de los derechos subjetivos de los Estados parte, sino también procuran la defensa de los intereses generales de la comunidad internacional.

4. Los tratados multipolares establecen obligaciones en cuyo cumplimiento se encuentra interesada la generalidad de todos los Estados parte. En este tipo de tratados el cumplimiento de las obligaciones se puede exigir por la totalidad de los Estados o, por un solo Estado a todos los demás. Los tratados multipolares suelen buscar tres objetivos fundamentales: a) La coordinación y armonización del derecho interno de los Estados parte; b) Establecer el principio de responsabilidad compartida reforzado con medidas de tipo preventivas - como la presentación de informes y la práctica de inspecciones - para hacer frente a un problema común - por ejemplo para la defensa de un "patrimonio común de la humanidad"- y c) Establecer estructuras de cooperación mediante la creación de instancias intergubernamentales. Por cuanto a su contenido, los tratados multipolares cuentan con cuatro características fundamentales: a) Fundan un verdadero orden jurídico objetivo, por lo que en ocasiones se les suele denominar "tratados ley"; b) Sus objetivos son la satisfacción de los intereses comunes de todos los Estados parte; c) Su diseño normalmente es abierto, facilitando la adhesión de nuevos Estados parte, pues existe interés general de que cada vez sean más Estados los que formen parte del acuerdo y $d$ ) La estructura de las obligaciones y sanciones refleja el interés que tienen todos los Estados parte para que las disposiciones del acuerdo se cumplan de igual manera por todos ellos. 
5. Los tratados multipolares establecen obligaciones erga omnes y, en consecuencia, hacen nacer derechos subjetivos en favor de todos los Estados parte. Con esto surgen relaciones jurídicas no entre Estados, sino entre cada Estado parte con todos los otros Estados parte. Las tradicionales sanciones de renuncia o suspensión pierden su significado y tienden a ser sustituidas por represalias o por la reparación del daño.

6. Los tratados multipolares desarrollan nuevos instrumentos de cumplimiento de las obligaciones. Dentro de éstos se encuentran instrumentos de prevención, de control, monitoreo, planificación, administración internacional - cooperación científica, organización de comisiones internacionales, establecimiento de estándares, coordinación de redes para intercambio de información-, etcétera. 